\title{
Survival after lobectomy versus sub-lobar resection in elderly with stage I NSCLC: a meta-analysis
}

\author{
Siyuan Dong ${ }^{1}$, Steven A. Roberts ${ }^{2}$, Shuang Chen $^{3}$, Xinwen Zhong ${ }^{1}$, Shize Yang ${ }^{1}$, Xiaohan $\mathrm{Qu}^{1}$ and Shun Xu ${ }^{1 *}$
}

\begin{abstract}
Background: We present a critical comparison of lobectomy and sub-lobar resection in elderly patients with early stage non-small cell lung cancer using meta-analytical techniques.

Methods: A literature search was conducted between the period of December 1997 to March 2019 to identify the comparative studies evaluating 1-, 3-, and 5-year survival rates. The pooled odds ratios (OR) and the 95\% confidence intervals $(95 \% \mathrm{Cl})$ were calculated with either the fixed or random effect models, respectively.

Results: Six retrospective studies are included in our meta-analysis for a total of 1205 patients. 843 of the individuals were treated with lobectomy, while 362 were treated with sub-lobar resection. We found no significant difference between the lobectomy and the sub-lobar resection in either of the 1-, 3-, or 5-year survival rates.

Conclusions: This study suggests that in elderly individuals with stage I NSCLC, a sub-lobar resection is statistically equivalent to the lobectomy in terms of 1-, 3-, and 5-year survival rates. Further large-scale randomized studies are needed to confirm our results.
\end{abstract}

Keywords: Lobectomy, Sub-lobar resection, Elderly, Stage I NSCLC

\section{Background}

Non-small cell lung cancer (NSCLC) is a leading cause of cancer-related deaths in individuals over 70 years old $[1,2]$, and its occurrence is likely to mirror the steady expansion of the elderly population.

Typically, treatment for localized stage I NSCLC consists of a lobectomy coupled with a systematic mediastinal lymphadenectomy [3]. While this treatment is generally accepted, recent reports have raised questions regarding the long term benefits of the lobectomy [4-6]. Alternatively, sub-lobar resection may provide an equivalent effect without many of the complications associated with lobectomy. To this end, Cancer and Leukemia Group B (CALGB) 140,503 [7] was established. This large, ongoing, multicenter randomized trial is currently evaluating whether sub-lobar resection is

\footnotetext{
* Correspondence: Xushun610539@sina.com

'Department of Thoracic Surgery, First Hospital of China Medical University,

155 North Nanjing Street, Shenyang, Liaoning, China

Full list of author information is available at the end of the article
}

equivalent to lobectomy for the therapy of stage IA NSCLC $2 \mathrm{~cm}$ in diameter.

Due to the specific characteristics and limited sample sizes of the geriatric population, the elderly are significantly underrepresented in clinical research [8]. To date, very little has been done to compare the two procedures. Aside from complications that may occur during surgery, the elderly are much more susceptible to operative mortality and postoperative respiratory complications, especially if underweight [9]. Both the risks and benefits of surgical treatment should be assessed in the treatment of these patients. To determine whether lobectomy improves survival compared with sub-lobar resection in elderly with stage I NSCLC, we conducted a meta-analysis of elderly with stage I NSCLC who underwent lobectomy or sub-lobar resection. We evaluated the short-term and long-term survival rates of these individuals to achieve a more objective appraisal of the published research and provide a more precise comparison between the two surgical approaches.

(c) The Author(s). 2019 Open Access This article is distributed under the terms of the Creative Commons Attribution 4.0 International License (http://creativecommons.org/licenses/by/4.0/), which permits unrestricted use, distribution, and reproduction in any medium, provided you give appropriate credit to the original author(s) and the source, provide a link to the Creative Commons license, and indicate if changes were made. The Creative Commons Public Domain Dedication waiver (http://creativecommons.org/publicdomain/zero/1.0/) applies to the data made available in this article, unless otherwise stated. 


\section{Methods}

\section{Search strategy}

Databases searched included the MEDLINE, Ovid MEDILINE, Cochrane Controlled Trial Register, Web of Science, PubMed and Embase databases in the period between December 1997 and March 2019. We included original research, reviews, meeting abstracts, editorials and letters as relevant sources of data. Search terms included, but not limited to: "lobectomy" "sub-lobar resection" "segmentectomy" "wedge resection" "elderly" "stage I" "non-small cell lung cancer" and "comparative study." Such as in the PubMed the search strategy is: "lobectomy"[$\mathrm{MeSH}$ ] or "lobectomy"[tiab] or "sub-lobar resection"[tiab] or "segmentectomy" [MeSH] or "segmentectomy" [tiab] or "wedge resection" [tiab] or "elderly" [tiab] or "stage I"[tiab] or "non-small cell lung cancer" $[\mathrm{MeSH}]$ or "non-small cell lung cancer" [tiab] or NSCLC $[\mathrm{MeSH}$ ] or NSCLC [tiab]. In cases where full texts weren't available, we contacted the corresponding authors to receive copies. Three authors (Shuang, Xinwen and Steven) independently searched the databases, while three authors (Shize, Shuang and Xinwen) independently reviewed 455 abstracts and 99 full texts independently. The Science Citation Index was used to cross-reference for further studies that meet the described criteria $[10,11]$.

\section{Study selection}

Studies were included in our meta-analysis if (1) they included a comparison of the efficacy of lobectomy to that of sub-lobar resection in elderly with stage I NSCLC (where the elderly here is defined as $\geq 70$ years); (2) they included a follow up $\geq 12$ months following the procedure, and (3) the patients' basic characteristics must be the same.

\section{Exclusion criteria}

We excluded studies if (1) the research did not include a comparative group with treatment as a method of intervention; (2) subjects were treated for stage II or III NSCLC; (3) the focused on patients undergoing surgery for metastatic lung tumor; (4) there was an overlap between patient cohorts, centers, or authors evaluated in the published studies(here only the latest results were included); (5) the study was published more than two decades ago.

\section{Data extraction and quality assessment}

The Downs and Black quality assessment method was used to evaluate the included articles [12]. This valuation includes 27 scoring standards, such as the clarity of the research objective, outcomes and characteristics of the patients, etc. Discrepancies between the three authors were solved by discussion among our team members and consensus with senior investigators (Siyuan and
Shun). The final results were confirmed by two senior researchers (Xinwen and Siyuan).

\section{Statistical analyses}

The Rev. Man 5.3.0. software package was used to conduct the meta-analysis. Odds ratio (OR) was calculated for the continuous outcomes while the mean difference with 95\% confidence intervals (95\% CI) was calculated for the dichotomous outcomes, respectively. A random-effects model and a fixed-effect model were used using"intention-to-treat" analysis. If results were not different between the two models, the random-effects model was reported, since this model was also used for the indirect comparisons. A significant difference between the two approaches was considered if the $P$ value $<0.05$. The $\mathrm{I}^{2}$ statistic was used to investigate the heterogeneity among the included trials [13]. The heterogeneity was explored by $\mathrm{I}^{2}$ and $\mathrm{X}^{2} ; \mathrm{I}^{2}<25 \%$ and $\mathrm{I}^{2}>50 \%$ reflect small and large inconsistencies, respectively. $P$ value $<0.05$ were considered significant.

\section{Publication bias}

Publication bias was assessed by constructing a funnel plot. The risk of bias of our research was evaluated by the asymmetry in the funnel plot of study size against curative efficacy.

\section{Results}

\section{Description of the studies}

Six retrospective cohort studies that met our predetermined criteria were included in the dataset. A total of 1205 elderly individuals were included in the six articles; 843 patients were distributed to the lobectomy group, and 362 patients were distributed to the sub-lobar resection group to evaluate their 1, 3 and 5-year survival rate. The search procedure, results of the search strategies and selection criteria are shown in Fig. 1. The evaluation index and patient's characteristics are summarized in Table 1.

\section{Evaluation of short and long term survival rate}

Five of the six studies reported the one-year survival result. We found no significant difference among these studies when evaluated using a fixed effect model $\left(\mathrm{X}^{2}=\right.$ $\left.0.45, P=0.93, \mathrm{I}^{2}=0 \%\right)$. The final combined outcome is shown in Fig. $2 \mathrm{a}(\mathrm{OR}=0.74 ; 95 \% \mathrm{CI} 0.43-1.27 ; P=0.27)$. In addition, five of the six studies reported three-year survival outcomes. We evaluated the heterogeneity of these results, again using the fixed effect model $\left(\mathrm{X}^{2}=\right.$ 9.25, $\left.P=0.06, \mathrm{I}^{2}=57 \%\right)$; these results are depicted in (Fig. 2b) $(\mathrm{OR}=0.99 ; 95 \% \mathrm{CI} 0.73-1.34 ; P=0.92)$. Finally, five of these six included studies included the five-year survival outcome $(\mathrm{OR}=1.03 ; 95 \% \mathrm{CI}, 0.80-1.34 ; P=0.80$. Unlike the one- and three-year survival data, we found a 


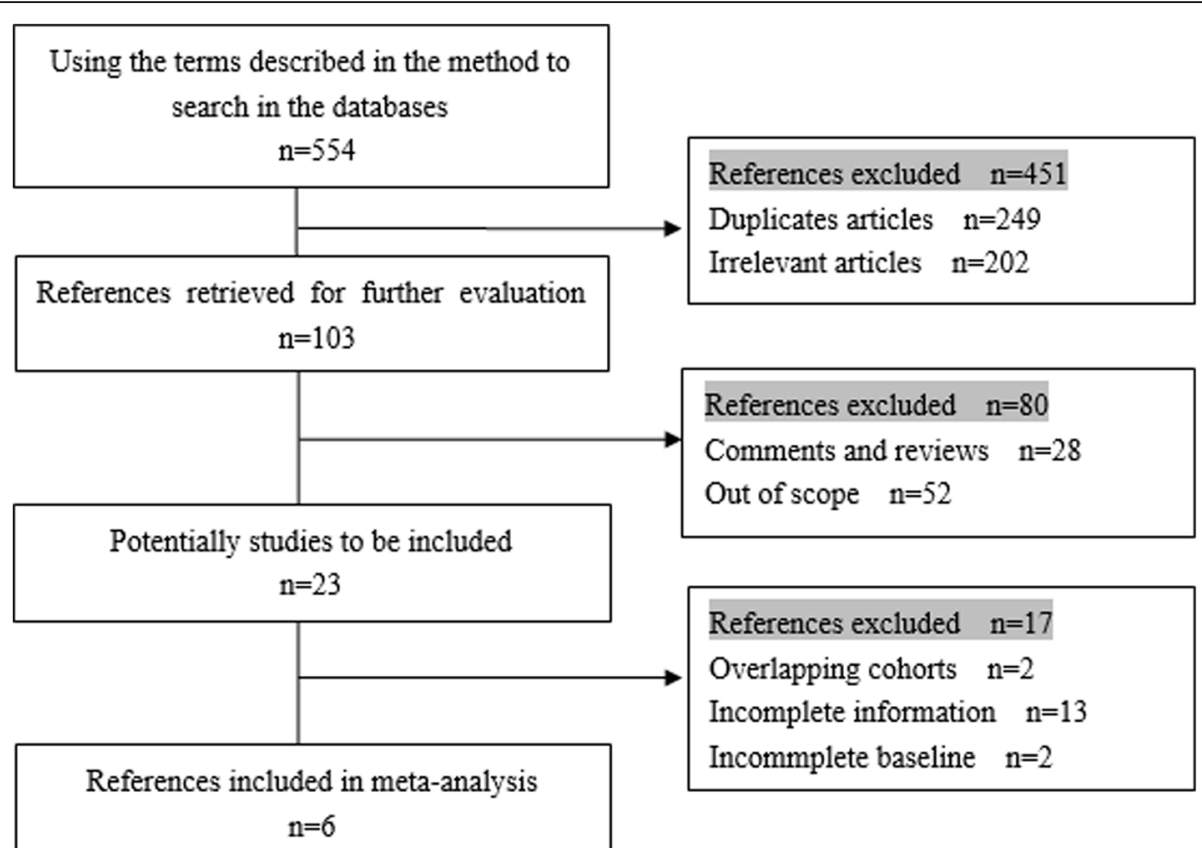

Fig. 1 Flow chart illustrating papers selected for analysis

statistically significant difference among these results $\left(\mathrm{x}^{2}\right.$ $=0.82, P=0.94, \mathrm{I}^{2}=0 \%$ ) (Fig. 2c). All of the outcomes were summarized in Table 2.

\section{Publication bias}

If non-significant results unpublished, there may be the publication bias occur. This has the effect of magnifying the apparent magnitude of the result artificially. The funnel plots of our meta-analysis are exhibited as Fig. 3. The funnel plot of the five-year survival receiving lobectomy and sub-lobar resection for the therapy of elderly with stage I non-small cell lung cancer manifested an asymmetry, revealing our research might contain publication bias.

\section{Discussion}

With the widespread use of high resolution computed tomography, more than $80 \%$ of pulmonary tumors are discovered at an early stage $[14,15]$. The global aging population is increasing rapidly [16], and the pulmonary malignant is a disease of generally occurring in the elderly. Effective and efficient therapies are pressing needed to cope with the dramatic increase in the amount of early-stage NSCLCs [17]. At present, the widely accepted surgical approach for the treatment of NSCLC is lobectomy with systematic mediastinal lymphadenectomy. This common practice of treatment was confirmed by Lung Cancer Study Group (LCSG) 821 trial which revealed that lobectomy contribute fewer local recurrences and relative improved long-term survival [18]. In addition, recent study by Luzzi's [19] et al. reported sub-lobar resection is followed with a significantly lower five-year survival compared with lobectomy (63\% vs. $90 \%$ ). However, these results may be obscured by comorbid illnesses such as COPD, diabetes and coronary artery disease, which are often present in elderly diagnosed

Table 1 The characteristics and evaluation index of the included studies

\begin{tabular}{lllllllllc}
\hline Study & Year & Design & Country & Mean age(L/S) & Gender(M/F) & NO(L/S) & NO(W/Se) & 5-y Survival \%(L/S) & $\begin{array}{c}\text { Assessment } \\
\text { Score }\end{array}$ \\
\hline Okami [26] & 2010 & OC & Japan & $77 / 78$ & $84 / 59$ & $79 / 54$ & $21 / 33$ & $74.3 / 67.6$ & 20 \\
Richard [20] & 2013 & OC & UK & $72 / 70$ & NR & $375 / 158$ & $158 / 0$ & $58.7 / 55.1$ & 18 \\
Zhang [42] & 2012 & OC & China & 83.6 & $39 / 13$ & $32 / 20$ & $16 / 4$ & $21.5 / 18.7$ & 17 \\
Lin [41] & 2013 & OC & China & $73 / 74$ & $29 / 18$ & $33 / 14$ & $14 / 0$ & NR & 19 \\
Andrea [30] & 2013 & OC & Italy & 78.1 & $257 / 62$ & $202 / 71$ & NR & $40.0 / 38.0$ & 15 \\
Liu [4] & 2014 & OC & China & $\geq 70$ & $96 / 71$ & $122 / 45$ & NR & $63.4 / 60.9$ & 14 \\
\hline
\end{tabular}

OC Observational cohort, $L$ Lobectomy, S Sub-Lobar Resection, NR Not reported, $W$ Wedge resection, Se Segmentectomy, $M$ Male, $F$ Female 


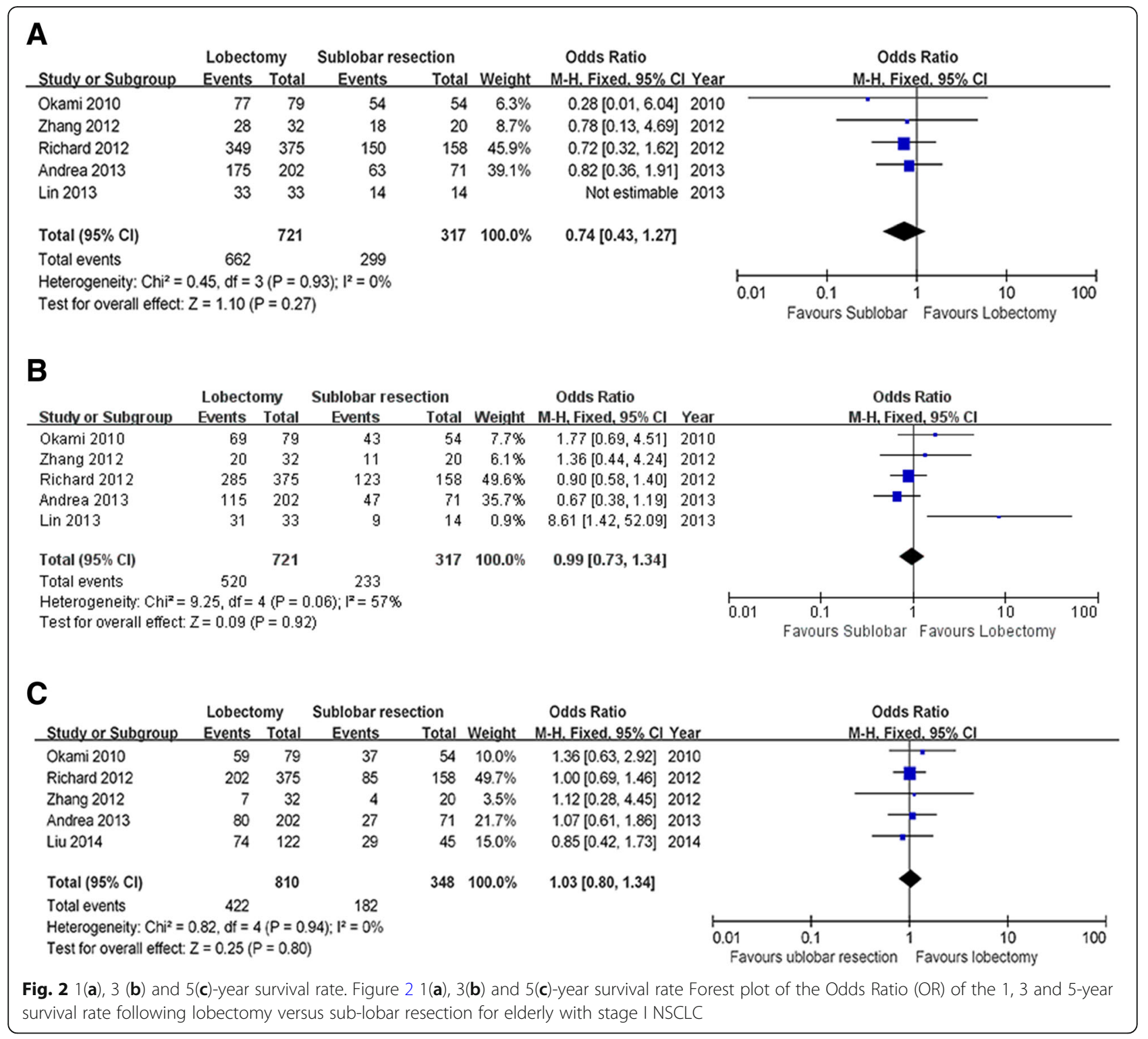

with NSCLC [20, 21]. The choice between sub-lobar resection versus lobectomy is influenced by the surgeon's and each institution's experience and preference. More evidence is needed to guide clinical decision-making that balances both therapeutic efficacy and surgical risk in this special population.

Table 2 Summary of the results between lobectomy and sublobar of elderly with stage I NSCLC

\begin{tabular}{lllllll}
\hline Variables & \multicolumn{2}{l}{ Results } & & OR & P-value & $I^{2}$ \\
\cline { 2 - 3 } & lobectomy & sub-lobar & & & \\
\hline 1-y survival & $91 \%$ & $94 \%$ & & 0.74 & 0.27 & $0 \%$ \\
3-y survival & $72 \%$ & $74 \%$ & & 0.99 & 0.92 & $57 \%$ \\
5-y survival & $52 \%$ & $52 \%$ & & 1.03 & 0.80 & $0 \%$ \\
\hline
\end{tabular}

Researchers who favor sub-lobar resection argue early stage NSCLCs are less aggressive than late stage [22, 23]. Analysis of the SEER database supports this conclusion; the survival outcomes for elderly patients with small peripheral tumors are comparable between lobectomy and sub-lobar resection [24]. These results have also been confirmed by the Japanese Joint Committee of Lung Cancer Registry [25]. In addition, research by other groups has demonstrated a high survival can be obtained by sub-lobar resection with a less extensive resection [5, 26-28]. A multivariate analyses by Brock et al. [29] showed poor respiratory function especially low FEV1, diminished physical status and tumor stage were associated with poor prognosis. As we know that the elderly are often associated with respiratory insufficiency [30]. Sub-lobar resections may provide an alternative of 


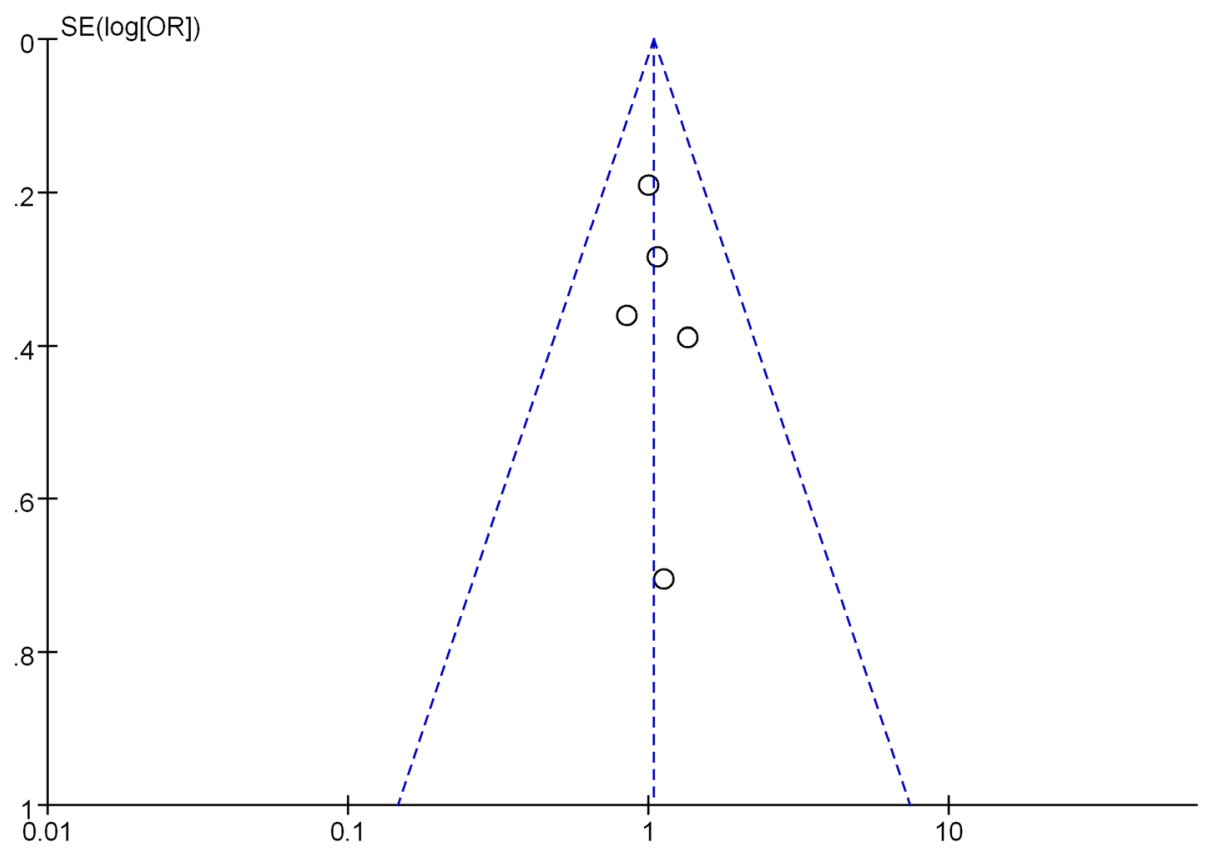

Fig. 3 Funnel plot of the outcome of five-year survival rate

raising resection rates in aged patient with both NSCLC and poor respiratory function, so the elderly with significant deterioration of respiratory reserve can benefit from sub-lobar resection rather than traditional standard lobectomy [31, 32]. And the sub-lobar resection group also obtained a lower percentage of post-operative complications, especially the respiratory complications. What's more, sub-lobar resection is accompanied with lower post-operative atelectasis, pneumonia and prolonged air leak rates than standard lobectomy group but without significant decreases in terms of in-hospital mortality [33].

In another aspect, researchers who emphasize that the lobectomy is helpful advocate that even the neoplasms which present localized by $\mathrm{CT}$ might already have micro-metastases. And there are researches that reveal sub-lobar resections are correlated with a significant increase of local recurrence [18, 34]. Study by EI-Sherif et al. conclude that, although sub-lobar resection result in a decreased rate of post-operative complications, it may also associated with lower disease-free survival [6]. What's more, DominguezVentura et al. reported that low forced expiratory volume in one second (FEV1) doesn't impact the survival [35]. Rami-Porta suggested that limited resections shouldn't be the first choice in patients who can accept standard lobectomy [36]. According to the European Respiratory Society/European Society of Thoracic Surgeons recommendations [37] and the American College of Chest Physician guidelines [38], for the reason that the heterogeneity in this specific population of aged patients, operation should not be denied only based on age. So other factors shouldn't be neglected, such as the overall physical condition.

It's remains a question of debate and inquiry that in the elderly whether sub-lobar resection is equivalent to standard lobectomy. To further test this hypothesis, all the candidates younger than 70-year were not included for the reason that these patients have both different baseline characteristics and life expectancies. This separates our current research from previous meta-analysis and randomized controlled trial in that this study examined only the subgroup of stage I NSCLC individuals that older than 70 years. This meta-analysis suggests that, for the elderly who are unsuitable to receive standard lobectomy, limited sub-lobar resection is an alternative which will get comparable benefits. We attribute this phenomenon to the following reasons: First of all, elderly with NSCLC are often afflicted with various comorbidities simultaneously, thus the perioperative management is more important and complex. The main reasons for equivalent oncological results in geriatric patients receiving limited sub-lobar resection compared to those who undergoing standard lobectomy are reduced postoperative complications, less surgical stress and better preservation of the pulmonary function [39]. Second, the geriatric patients are often associated with other age-related diseases and have a short life expectancy. As a result, they typically succumb of diseases other than lung cancer [4]. Lastly, NSCLC in the elderly may be less invasive than in younger individuals [39]. Although they 
did not receive the standard operation, they also could get the almost equivalent outcomes. During the study we evaluated the recurrence rate of the two approaches to further substantiate our conclusions. However, we found the data was too limited to adequately compare the two groups. Because unexpected lymph node metastases are found during the operation in not less than $10 \%$ of patients with an early lesion, so routine PET-scanning is suggested [40]. And during the operation, mediastinal lymph node sampling is also suggested.

This study is the first meta-analysis focusing the oncological outcome of sub-lobar resection for the treatment of elderly with early-stage NSCLC. In our work, we observed that sub-lobar resection allowed for surgical resection in elderly with stage I NSCLC without compromising oncological results. However, currently there are no large randomized trials can corroborate these finding, and in most cases, retrospective findings are limited to a single institution and small observational studies. Lobar versus sub-lobar resection remains to be a controversial topic. The thoracic community awaits the results from two ongoing randomized clinical trials from the US (CALBG 140503, clinicaltrials.gov number: NCT00499330) and from Japan (JCOG 0802, UMIN Clinical Trials Registry: UMIN000001272) to further elucidate the outcome after sub-lobar resections. And more prospective randomized studies comparing the two different surgical strategies are needed. The funnel plot was presented with annotation that it showed asymmetry and it might suggest the publication bias. As we know, the standard surgical therapy for stage I NSCLC is still the lobectomy, if the researches got the same conclusion in the elderly population, the researcher might abandon to publish the work. So our research might have publication bias.

However, there are several limitations in our research. No randomized controlled trials existing in this field to compare lobectomy with sub-lobar resection have been conducted. Most studies are limited to single institution case series and small observational studies. Because of this, there are only a total of 1205 elderly were included in the two groups. Two of all the included researches comprise almost $66 \%$ of all the elderly, and one study contains only 47 patients. Lobar versus sub-lobar resection remains to be a controversial topic and many studies have been published over the last 10 years. They all suffers the same problem that data did not take into consideration the differences in patient selection for sub-lobar resection. Was it because of age, comorbidity or poor lung function? Was it because of GGO? The defect of this article is that there are so many discrepancies among centers on their policy, procedures, and philosophy.
Although we confined all the studies regarding stage I NSCLC. The subtypes of NSCLC were not classified in the included studies [41]. They may also affect the survival and recurrence. Additional randomized controlled trials in the studies we accessed would have increased the strength of our results. Last, there were no data available to distinguish between patients who did or did not receive adjuvant chemo-radiation therapy. Our research include six articles, publication bias evaluation using funnel plots is not ideal when total number of publications included in the pooled analysis are less than ten. So inability to assess publication bias accurately using funnel plots maybe exist in our research. There is also a bias for the English language.

\section{Conclusion}

In our meta-analysis, we found that for elderly with stage I NSCLC, comparing lobectomy with sub-lobar resection showed almost equivalent survival rates. Further study is needed, and a large multicenter randomized trial comparing lobectomy with sub-lobar resection for the elderly with stage I NSCLC would be ideal.

\section{Abbreviations \\ 95\% Cl: 95\% confidence intervals; FEV1: Forced expiratory volume in one second; NSCLC: Non-small cell lung cancer; OR: Odds ratios}

\section{Acknowledgments}

None.

\section{Funding}

This research was supported by the National Nature Science Foundation of China (81702242) for data collection and Doctoral Scientific Research

Foundation of Liaoning Province (20170520441) for language editing.

Availability of data and materials

All data generated or analyzed during this study are included in this published article.

Authors' contributions

SYD, SX and XWZ design the study; SC, SAR and SZY collected the data; SYD and XHQ wrote the manuscript; SAR and SYD revised the manuscript; all the authors read and approved the final manuscript.

Ethics approval and consent to participate Not applicable.

Consent for publication

Not applicable.

Competing interests

The authors declare that they have no competing interests.

\section{Publisher's Note}

Springer Nature remains neutral with regard to jurisdictional claims in published maps and institutional affiliations.

\section{Author details}

${ }^{1}$ Department of Thoracic Surgery, First Hospital of China Medical University, 155 North Nanjing Street, Shenyang, Liaoning, China. ${ }^{2}$ Ott lab, Massachusetts General Hospital, Harvard Medical School, 185 Cambridge Street, Boston, 
USA. ${ }^{3}$ Department of Cardiovascular, First Hospital of China Medical University, 155 North Nanjing Street, Shenyang, Liaoning, China.

\section{Received: 2 February 2018 Accepted: 29 March 2019 Published online: 15 April 2019}

\section{References}

1. DeSantis CE, Lin CC, Mariotto AB, Siegel RL, Stein KD, Kramer JL, Alteri R, Robbins AS, Jemal A. Cancer treatment and survivorship statistics, 2014. CA Cancer J Clin. 2014;64(4):252-71.

2. Yancik R, Ries LA. Aging and cancer in America. Demographic and epidemiologic perspectives. Hematol Oncol Clin North Am. 2000;14(1):1723.

3. Donington JS, Kim YT, Tong B, Moreira AL, Bessich J, Weiss KD, Colson YL, Wigle D, Osarogiagbon RU, Zweig J, et al. Progress in the Management of Early-Stage non-Small Cell Lung Cancer in 2017. J Thorac Oncol. 2018;13(6): 767-78.

4. Liu T, Liu H, Li Y. Early lung cancer in the elderly: sublobar resection provides equivalent long-term survival in comparison with lobectomy. Contemp Oncol (Pozn). 2014;18(2):111-5.

5. De Zoysa MK, Hamed D, Routledge T, Scarci M. Is limited pulmonary resection equivalent to lobectomy for surgical management of stage I nonsmall-cell lung cancer? Interact Cardiovasc Thorac Surg. 2012;14(6):816-20.

6. El-Sherif A, Gooding WE, Santos R, Pettiford B, Ferson PF, Fernando HC, Urda SJ, Luketich JD, Landreneau RJ. Outcomes of sublobar resection versus lobectomy for stage I non-small cell lung cancer: a 13-year analysis. Ann Thorac Surg. 2006;82(2):408-15 discussion 415-406.

7. Kohman L, Gu L, Altorki N, Scalzetti E, Veit LJ, Wallen JM, Wang X. Biopsy first: lessons learned from Cancer and leukemia group B (CALGB) 140503. J Thorac Cardiovasc Surg. 2017;153(6):1592-7.

8. Edwards BK, Howe HL, Ries LA, Thun MJ, Rosenberg HM, Yancik R, Wingo $P A$, Jemal A, Feigal EG, Annual report to the nation on the status of cancer, 1973-1999. Featuring implications of age and aging on U.S. cancer burden. Cancer. 2002;94(10):2766-92.

9. Wang C, Guo M, Zhang N, Wang G. Association of body mass index and outcomes following lobectomy for non-small-cell lung cancer. World J Surg Oncol. 2018:16(1):90.

10. Dong S, Zhang L, Li W, Du J, Liu X, Chen X. Evaluation of video-assisted thoracoscopic surgery for pulmonary metastases: a meta-analysis. PLoS One. 2014;9(1):e85329.

11. Dong S, Du J, Li W, Zhang S, Zhong X, Zhang L. Systematic mediastinal lymphadenectomy or mediastinal lymph node sampling in patients with pathological stage I NSCLC: a meta-analysis. World J Surg. 2015;39(2):410-6.

12. Downs SH, Black N. The feasibility of creating a checklist for the assessment of the methodological quality both of randomised and non-randomised studies of health care interventions. J Epidemiol Community Health. 1998; 52(6):377-84.

13. Huedo-Medina TB, Sanchez-Meca J, Marin-Martinez F, Botella J. Assessing heterogeneity in meta-analysis: Q statistic or 12 index? Psychol Methods. 2006;11(2):193-206.

14. Veronesi G, Bellomi M, Mulshine JL, Pelosi G, Scanagatta P, Paganelli G, Maisonneuve P, Preda L, Leo F, Bertolotti R, et al. Lung cancer screening with low-dose computed tomography: a non-invasive diagnostic protocol for baseline lung nodules. Lung Cancer. 2008;61(3):340-9.

15. Loo BW Jr. Stereotactic ablative radiotherapy (SABR) for lung cancer: what does the future hold? J Thorac Dis. 2011;3(3):150-2

16. Pallis AG, Gridelli C, van Meerbeeck JP, Greillier L, Wedding U, Lacombe D, Welch J, Belani CP, Aapro M. EORTC elderly task force and lung Cancer group and International Society for Geriatric Oncology (SIOG) experts' opinion for the treatment of non-small-cell lung cancer in an elderly population. Ann Oncol. 2010;21(4):692-706.

17. Smith BD, Smith GL, Hurria A, Hortobagyi GN, Buchholz TA. Future of cancer incidence in the United States: burdens upon an aging, changing nation. J Clin Oncol. 2009;27(17):2758-65.

18. Ginsberg RJ, Rubinstein LV. Randomized trial of lobectomy versus limited resection for T1 N0 non-small cell lung cancer. Lung Cancer study group. Ann Thorac Surg. 1995;60(3):615-22 discussion 622-613

19. Luzzi L, Marulli G, DEP A, Meniconi F, Ghisalberti M, Stocca F, Pagliarulo V, Loizzi M, Rea F, Gotti G. Prognostic factors and clinical outcome in patients with surgically resected peripheral N0 adenocarcinoma $<3 \mathrm{~cm}$. Minerva Chir. 2016;71(1):1-7.
20. Warwick R, Mediratta N, Shackcloth M, Page R, McShane J, Shaw M, Poullis M. Wedge resection verses lobectomy for stage 1 non-small-cell lung cancer. Asian Cardiovasc Thorac Ann. 2013;21(5):566-73.

21. Zhang J, Xue Z-Q, Chu X-Y, Wang Y-X, Zhao J-H, Xu C, Yin L-G. Surgical treatment and prognosis of octogenarians with non-small cell lung cancer. Asian Pac J Trop Med. 2012:5(6):465-8.

22. Okada M, Koike T, Higashiyama M, Yamato Y, Kodama K, Tsubota N. Radical sublobar resection for small-sized non-small cell lung cancer: a multicenter study. J Thorac Cardiovasc Surg. 2006;132(4):769-75.

23. Harpole DH Jr, Herndon JE 2nd, Young WG Jr, Wolfe WG, Sabiston DC Jr. Stage I nonsmall cell lung cancer. A multivariate analysis of treatment methods and patterns of recurrence. Cancer. 1995;76(5):787-96.

24. Mery CM, Pappas AN, Bueno R, Colson YL, Linden P, Sugarbaker DJ, Jaklitsch MT. Similar long-term survival of elderly patients with non-small cell lung cancer treated with lobectomy or wedge resection within the surveillance, epidemiology, and end results database. Chest. 2005;128(1):237-45.

25. Okami J, Higashiyama M, Asamura H, Goya T, Koshiishi Y, Sohara Y, Eguchi K Mori M, Nakanishi $Y$, Tsuchiya $R$, et al. Pulmonary resection in patients aged 80 years or over with clinical stage I non-small cell lung cancer: prognostic factors for overall survival and risk factors for postoperative complications. J Thorac Oncol. 2009:4(10):1247-53.

26. Okami J, Ito Y, Higashiyama M, Nakayama T, Tokunaga T, Maeda J, Kodama K. Sublobar resection provides an equivalent survival after lobectomy in elderly patients with early lung cancer. Ann Thorac Surg. 2010;90(5):1651-6.

27. Dembitzer FR, Flores RM, Parides MK, Beasley MB. Impact of histologic subtyping on outcome in lobar vs sublobar resections for lung cancer: a pilot study. Chest. 2014;146(1):175-81.

28. Tsutani Y, Miyata Y, Nakayama H, Okumura S, Adachi S, Yoshimura M, Okada M. Appropriate sublobar resection choice for ground glass opacitydominant clinical stage IA lung adenocarcinoma: wedge resection or segmentectomy. Chest. 2014;145(1):66-71

29. Brock MV, Kim MP, Hooker CM, Alberg AJ, Jordan MM, Roig CM, Xu L, Yang SC. Pulmonary resection in octogenarians with stage I nonsmall cell lung cancer: a 22-year experience. Ann Thorac Surg. 2004;77(1):271-7.

30. Dell'Amore A, Monteverde M, Martucci N, Sanna S, Caroli G, Stella F, Dell'Amore D, Rocco G. Early and long-term results of pulmonary resection for non-small-cell lung cancer in patients over 75 years of age: a multiinstitutional study. Interact Cardiovasc Thorac Surg. 2013;16(3):250-6.

31. Martin-Ucar AE, Nakas A, Pilling JE, West KJ, Waller DA. A case-matched study of anatomical segmentectomy versus lobectomy for stage I lung cancer in high-risk patients. Eur J Cardiothorac Surg. 2005;27(4):675-9.

32. Lim E, Baldwin D, Beckles M, Duffy J, Entwisle J, Faivre-Finn C, Kerr K, Macfie A, McGuigan J, Padley S et al: Guidelines on the radical management of patients with lung cancer. Thorax 2010, 65 Suppl 3:iii1-27.

33. Dell'Amore A, Monteverde M, Martucci N, Sanna S, Caroli G, Dolci G, Dell'Amore D, Rocco G. Lobar and sub-lobar lung resection in octogenarians with early stage non-small cell lung cancer: factors affecting surgical outcomes and long-term results. Gen Thorac Cardiovasc Surg. 2015; 63(4):222-30.

34. Warren WH, Faber LP. Segmentectomy versus lobectomy in patients with stage I pulmonary carcinoma. Five-year survival and patterns of intrathoracic recurrence. J Thorac Cardiovasc Surg. 1994;107(4):1087-93 discussion 1093-1084

35. Dominguez-Ventura A, Allen MS, Cassivi SD, Nichols FC 3rd, Deschamps C, Pairolero PC. Lung cancer in octogenarians: factors affecting morbidity and mortality after pulmonary resection. Ann Thorac Surg. 2006:82(4):1175-9.

36. Rami-Porta R, Tsuboi M. Sublobar resection for lung cancer. Eur Respir J. 2009:33(2):426-35.

37. Brunelli A, Charloux A, Bolliger CT, Rocco G, Sculier JP, Varela G, Licker M, Ferguson MK, Faivre-Finn C, Huber RM, et al. The European Respiratory Society and European Society of Thoracic Surgeons clinical guidelines for evaluating fitness for radical treatment (surgery and chemoradiotherapy) in patients with lung cancer. Eur J Cardiothorac Surg. 2009;36(1):181-4

38. Colice GL, Shafazand S, Griffin JP, Keenan R, Bolliger CT. Physiologic evaluation of the patient with lung cancer being considered for resectional surgery: ACCP evidenced-based clinical practice guidelines (2nd edition). Chest. 2007:132(3 Suppl):161s-77s.

39. Dominguez-Ventura A, Cassivi SD, Allen MS, Wigle DA, Nichols FC, Pairolero PC, Deschamps C. Lung cancer in octogenarians: factors affecting long-term survival following resection. Eur J Cardiothorac Surg. 2007;32(2):370-4.

40. Thomas PA. Lymph node dissection during sublobar resection: why, when and how? J Thorac Dis. 2018;10(Suppl 10):S1145-s1150. 
41. Lin L, Hu D, Zhong C, Zhao H. Safety and efficacy of thoracoscopic wedge resection for elderly high-risk patients with stage I peripheral non-small-cell lung cancer. J Cardiothorac Surg. 2013;8:231.

42. Zhang J, Xue ZQ, Chu XY, Wang YX, Zhao JH, Xu C, Yin LG. Surgical treatment and prognosis of octogenarians with non-small cell lung cancer. Asian Pac J Trop Med. 2012;5(6):465-8.

Ready to submit your research? Choose BMC and benefit from:

- fast, convenient online submission

- thorough peer review by experienced researchers in your field

- rapid publication on acceptance

- support for research data, including large and complex data types

- gold Open Access which fosters wider collaboration and increased citations

- maximum visibility for your research: over $100 \mathrm{M}$ website views per year

At BMC, research is always in progress.

Learn more biomedcentral.com/submissions 